\title{
O uso na preservação arquitetônica do patrimônio industrial da cidade de São
}

\section{Paulo}

Angela Rösch Rodrigues*

Mônica Junqueira de Camargo**

\section{Resumo}

Este artigo pretende analisar como a questão do uso do patrimônio arquitetônico vem sendo abordada através de alguns dos principais textos relacionados com as teorias preservacionistas e os preceitos de restauração de estudiosos a partir do século 19. A partir desse panorama, propõe-se uma reflexão relacionando esse tema com a preservação do patrimônio industrial na atualidade enfocando a cidade de São Paulo, uma vez que esse patrimônio, devido a um conjunto de características, tende a ser considerado exclusivamente no âmbito econômico direcionando uma determinada postura em relação à funcionalidade que geralmente não abrange o real escopo da preservação patrimonial.

Palavras chave: Preservação arquitetônica industrial. Patrimônio industrial, São Paulo, SP, Brasil.

\section{The use in the architecture preservation of São Paulo city industrial heritage}

\begin{abstract}
This article aims to examine how the issue of using architectural heritage has being studied by some of the most important scholars from the nineteenth century and their texts related to the theories and precepts preservationists. With this background, it is proposed to reflect this theme relating to the preservation of industrial heritage in nowadays focusing on the city of São Paulo. Due to a number of characteristics, industrial heritage tends to be considered only by an economical point of view and the utilization of this heritage is not considering inside of the actual scope of the preservation.
\end{abstract}

Key -words: Preservation of industrial architecture. Industrial heritage, São Paulo, SP, Brazil. 


\section{Introdução}

A preservação do patrimônio cultural abrange diversos aspectos daquilo que é considerado monumento histórico. No caso dos bens arquitetônicos essa discussão relaciona-se intimamente com uma de suas características intrínsecas, o uso: "A arquitetura é a única, entre as artes maiores, cujo uso faz parte de sua essência e mantém uma relação complexa com suas finalidades estética e simbólica" (CHOAY, 2001, p. 230).

A funcionalidade de uma obra arquitetônica suscita diversas reflexões, pois, além de seu papel simbólico relativo às representações sociais, é amplamente reconhecida a necessidade de uma destinação útil para a preservação de qualquer bem, já que o abandono é uma das principais causas da degradação dos monumentos. Todavia, a imposição de uma destinação incongruente aumenta o risco de sua destruição. Desse modo, o levantamento de um determinado bem e seus usos, passa a ser de extrema importância para o campo da preservação arquitetônica, tanto que vem sendo abordado por diversos teóricos, principalmente a partir da segunda metade do século 19, quando deixa de se relacionar exclusivamente com intervenções de ordem prática e outros valores (formais, históricos, simbólicos e memoriais) são incorporados à discussão, tornando-a um ato cultural.

Este artigo pretende analisar historicamente a questão do uso do patrimônio edificado, recuperando as várias abordagens nos principais textos relacionados com as teorias preservacionistas e os preceitos de restauração de alguns estudiosos, a partir do século 19. A partir desse panorama, passaremos a verificar sua implicação na preservação do patrimônio industrial, pois as diversas formas de apropriação e intervenção que incidem sobre esse patrimônio na atualidade tangenciam diretamente a questão do uso mediante as referências do campo preservacionista. Para tanto será utilizado como referência o patrimônio industrial da cidade de São Paulo, um rico acervo que evidencia o desenvolvimento econômico e urbano da capital paulista constituído de remanescentes de reconhecido valor cultural, muitos já bastante adulterados.

\section{A questão do uso nas teorias preservacionistas}


A necessidade de adaptar e intervir é intrínseca à história da preservação dos objetos arquitetônicos. Durante séculos, as intervenções em edifícios existentes tinham como principal objetivo a sua adequação às necessidades e exigências contemporâneas, podendo variar desde o reuso dos materiais, destruição e abandono total decorrentes da perda de função como em templos pagãos, anfiteatros, dentre outros, até reconstruções, alterações no projeto original e adaptação para novos usos, como no caso das basílicas romanas, construções laicas reutilizadas para funções religiosas (LEMOS, 2006, p. 13). Aspectos sociais, políticos, ideológicos, religiosos, econômicos aliados à crença na linearidade do desenvolvimento contínuo das artes, ao progresso e à evolução formal foram determinantes para não abarcar o valor cultural dos monumentos enquanto herança a ser preservada.

Entre os séculos 15 e 19 verifica-se um longo processo de sedimentação das ideias preservacionistas, cuja maturação se deu a partir do século 19. O Renascimento italiano aponta uma nova relação com a cultura de épocas precedentes, introduzindo uma avaliação crítica em relação às obras do passado recente e de exaltação da herança da Antiguidade Clássica, não só pelo aspecto histórico, mas também pelo artístico. Um exemplo interessante dessa ainda incipiente noção sobre a relevância do uso para a preservação e o restauro, foi a postura de Michelangelo (1475-1564) quando chamado para a transformação das Termas de Diocleciano em Igreja Santa Maria dos Anjos, onde inseriu apenas os elementos necessários de forma criativa e criteriosa adequando para a nova função, respeitando a espacialidade original e preservando o aspecto de ruína exterior, proposta muito próxima aos conceitos de mínima intervenção mais recentes (KÜHL, 2001, p. 24-36).

No século 18, com a descoberta dos sítios arqueológicos de Pompeia e Herculano, veio à tona a questão fundamental da descontinuidade evidente entre um passado remoto e o presente, e as consequentes restrições em se apropriar desse legado, até então sepultado, às necessidades contemporâneas.

Com o desenvolvimento proporcionado pela Revolução Industrial e as consequências desencadeadas pela Revolução Francesa, a compreensão sobre o monumento histórico enquanto instrumento de preservação de memória coletiva e 
as respectivas formas de intervir foram se transformando. Discussões e debates intensificaram-se durante o século 19 e algumas posições se estruturaram, dentre elas a polarização das ideias não intervencionistas de John Ruskin (1819-1900) na Inglaterra e as intervencionistas de Eugène Emmanuel Viollet-le-Duc (1814-1879) na França.

Ruskin, em seu texto "As Sete Lâmpadas da Arquitetura", de 1849, especificamente no Capítulo VI - "A Lâmpada da Memória", apresentou importantes conceitos que fomentaram a postura não intervencionista, como o respeito à arquitetura menor, a atribuição veemente da questão da herança, que se recebe e que se transmite, a conservação como uma necessidade anterior à restauração entendida como último recurso, porém, não há qualquer menção em relação à forma pela qual os edifícios deveriam ser apropriados em termos utilitários. Ruskin se concentrou no aspecto pictórico das ruínas que acabou por desviá-lo da questão funcional dos monumentos, tema desconsiderado em suas teorias.

Já a postura intervencionista polarizada nas idéias de Viollet-le-Duc, defendia de forma contundente a necessidade de um uso às edificações, como pode ser detectado em seu verbete "Restauração" publicado entre 1854 a 1868:

Ademais, o melhor meio para conservar um edifício é encontrar para ele uma destinação, e satisfazer tão bem todas as necessidades que exige essa destinação, que não haja modo de fazer modificações. (VIOLLET-LE-DUC, 2000, p. 65).

O autor ressaltou ainda a importância do papel do restaurador na compreensão do aspecto utilitário da edificação:

\footnotetext{
Uma vez que todos os edifícios nos quais se empreende uma restauração têm uma destinação, são designados para uma função, não se pode negligenciar esse lado prático para se encerrar totalmente no papel de restaurador de antigas disposições fora de uso. Proveniente das mãos do arquiteto, o edifício não deve ser menos cômodo do que era antes da restauração. (VIOLLET-LE-DUC, 2000, p. 64).
}

Viollet-le-Duc, evidenciando as características da sua postura intervencionista, justifica que adaptações são necessárias para se obter o conforto contemporâneo, dado fundamental para a preservação de qualquer bem: 
Que um arquiteto se recuse a fazer com que tubos de gás passem dentro de uma igreja a fim de evitar mutilações e acidentes é compreensível, pois é possível iluminar o edifício com outros meios; mas que não consinta na instalação de um calorífero, por exemplo, sob o pretexto de que a Idade Média não havia adotado esse sistema de aquecimento nos edifícios religiosos, que ele obrigue assim os fiéis a se resfriar por causa da arqueologia, isso cai no ridículo. Uma vez que esses meios de aquecimento exigem tubos de chaminé, ele deve proceder como teria feito um mestre da Idade Média se estivesse na obrigação de instalá-lo [...]. (VIOLLET-LE-DUC, 2000, p. 66).

Em fins do século 19 a discussão sobre intervenções e preservação em monumentos adquiriu grande dimensão abrangendo diversos países europeus. $\mathrm{Na}$ Itália, Camillo Boito (1836-1914) desenvolveu trabalhos teóricos relevantes ao restauro sintetizando de forma crítica a polarização das posturas não intervencionista e intervencionista. A reformulação de Boito estabeleceu o denominado "restauro científico" ou "filológico" caracterizado pela abordagem estritamente documental do monumento e por certa repercussão das ideias positivistas, evidenciadas pela forma classificatória com a qual apresenta distinções e sistematizações. Boito delineou importantes princípios que embasam a teoria contemporânea, dentre eles, a importância da "distinguibilidade e mínima intervenção" (KÜHL, 2002, p. 27). Contudo, em relação aos aspectos funcionais, Boito não se refere especificamente.

Já o teórico austríaco Alois Riegl (1858-1905) deu especial destaque à questão do uso. Riegl participou da reformulação da legislação austríaca em relação à preservação, e escreveu, em 1903, "O Culto Moderno dos Monumentos", que embasou o novo projeto de lei proposto. Contemplando os aspectos psicossociais e a recepção e percepção das obras, Riegl esquematizou uma série de valores para a compreensão dos monumentos, segmentando-os em valores de "rememoração" e de "contemporaneidade", dentre os quais se insere o "valor de uso" que segundo ele não pode ser eliminado (RIEGL, 1990, p. 59).

A partir da análise dos diversos valores e suas relações, Riegl estabeleceu a dimensão funcional para a preservação de um monumento, esclarecendo que a ausência de uma função pode comprometer a integridade do bem. Segundo ele, a sensação de ver uma edificação que possuía um uso e que passou a não tê-lo mais 
pode proporcionar um súbito sentimento de destruição violenta. E no caso dos edifícios que já conhecemos sem uso, a falta de uma atividade humana não é tão perturbadora (como as ruínas de um castelo medieval, ou de um templo romano), distinguindo, dessa forma, as obras mais antigas das mais recentes, e de modo semelhante, as obras mais suscetíveis a serem utilizáveis ou não (RIEGL, 1990, p. $60)$.

No início do século 20, Gustavo Giovannoni (1873-1947) desenvolveu pontos de interesse a partir do repertório filológico delineado por Boito. No que tange ao uso Giovannoni avançou a questão através das seguintes distinções no Verbete escrito em 1936 para a Enciclopédia Italiana: "monumentos mortos" mais antigos como os da antiguidade clássica, aos quais normalmente se exclui uma utilização atual e "monumentos vivos", mais recentes como palácios e igrejas aos quais é oportuno reportá-los a uma nova função, não muito diversa da original (GIOVANNONI, 1936, p. 128).

Essa matriz italiana foi determinante na formulação da Carta de Atenas de 1931 documento internacional inaugural do campo da preservação. Dentre os princípios gerais da carta foi enunciada a utilização dos monumentos, contanto respeitosa, compatível com suas especificidades, de modo a não sobrepor a necessidade de um novo uso à preservação: "A - I: [...] A conferência recomenda que se mantenha uma utilização dos monumentos, que assegure a continuidade de sua vida, [...]" (SOCIEDADE..., 1931, p. 1).

Nas duas décadas que se seguiram à Segunda Guerra Mundial, em decorrência à destruição massiva e às diversas experiências na área do restauro embasadas nas especificações da Carta de Atenas de 1931, verifica-se paulatinamente a necessidade de revisão e aprimoramento do restauro como campo disciplinar. Nesse contexto, Cesare Brandi (1906-1988), desenvolveu a "Teoria da Restauração", publicada em 1963, na qual estabeleceu parâmetros metodológicos para a restauração da obra de arte reconhecida como tal.

Na teoria brandiana, a questão da função relaciona-se diretamente com o sentido da restauração e com o reconhecimento da obra de arte, sendo que a instância do uso 
fica condicionada à artisticidade da obra, dessa forma o restauro tem caráter específico e diverso das intervenções que têm como prioridade o mero restabelecimento da funcionalidade:

\begin{abstract}
$\mathrm{Na}$ verdade, quando se tratar de produtos industriais - entendendo-se isso na mais ampla escala, que parte do mais diminuto artesanato -, o escopo da restauração será evidentemente restabelecer a funcionalidade do produto, estando, por isso, a natureza da intervenção de restauro ligada de forma exclusiva à realização desse fim. Mas, quando se tratar, ao contrário, de obra de arte, mesmo se entre as obras de arte haja algumas que possuam estruturalmente um objeto funcional, como as obras de arquitetura e, em geral, os objetos da chamada arte aplicada, claro estará que o restabelecimento da funcionalidade, se entrar na intervenção de restauro, representará, definitivamente só um lado secundário ou concomitante, e jamais o primário e fundamental que se refere à obra de arte como obra de arte. (BRANDI, 2004, p. 26).
\end{abstract}

É necessário salientar que a restauração, como entendida a partir do século 19, trata do maior nível de intervenção que um monumento pode receber após um período de degradação. Mas o campo da preservação engloba outras medidas anteriores a esse nível como a conservação e manutenção que também devem ser orientadas tomando como referência o critério da mínima intervenção. Nesse sentido, Brandi refere-se ao conceito de "restauração preventiva" (BRANDI, 2004, p. 101) em que estão implícitas medidas de prevenção e conservação, salientando que a restauração preventiva é ainda mais imperativa, pois objetiva impedir as intervenções de extrema urgência.

Mediante a massiva destruição decorrente da Segunda Guerra Mundial e a necessidade de reconstrução em caráter de urgência de núcleos centrais inteiros, aspectos da carta patrimonial de 1931 foram reavaliados. A partir dessas discussões formulou-se um novo documento denominado Carta de Veneza, definido no II Congresso Internacional de Arquitetos e Técnicos dos Monumentos Históricos em 1964. Esta carta delineou uma unidade metodológica para as intervenções nos bens culturais, inserindo a restauração no quadro social, econômico e cultural. Esse documento permanece válido até hoje para os países signatários. A questão do uso passou então a ter a seguinte recomendação: 
Artigo $5^{\circ}$ - A conservação dos monumentos é sempre favorecida por sua destinação a uma função útil à sociedade; tal destinação é, portanto, desejável, mas não pode nem deve alterar a disposição ou a decoração dos edifícios. É somente dentro destes limites que se deve conceber e se podem autorizar as modificações exigidas pela evolução dos usos e costumes. (ICOMOS, 1964).

Nos últimos anos, o interesse pelo patrimônio edificado tem aumentado consideravelmente, não só pela maior consciência do seu valor histórico, mas também por razões outras como o aumento demográfico, a saturação territorial, a complexidade urbana que acarreta diversos problemas político-econômicos vinculados, por exemplo, à especulação imobiliária e à exploração do turismo. Assim, o uso do patrimônio edificado existente como fonte cultural, social e econômica tornou-se uma questão de grande interesse, que extrapola a questão meramente preservacionista. A Carta Europeia de Patrimônio Arquitetônico, promulgada em 1975 em Amsterdã, evidencia a necessária leitura do aspecto preservacionista sob a ótica do desenvolvimento urbano na medida em que propõe, justamente, uma ação conjunta entre as técnicas de restauro e a pesquisa de funções compatíveis, com o objetivo principal de uma conservação integrada no âmbito do planejamento urbano e territorial, para a definição de uma estratégia única para os meios técnicos, administrativos e financeiros (CARBONARA, 1997, p. 375).

Segundo pesquisadores como Giovanni Carbonara (1942), que defende a abrangência e aplicabilidade da teoria brandiana na atualidade, o maior problema da preservação reside, justamente, na compreensão e reconhecimento do patrimônio edificado como bem cultural. Para este autor, somente a partir do reconhecimento da significação histórico-artística, e considerando todos os princípios e instrumentos metodológicos desse consolidado campo disciplinar é que se pode estabelecer os critérios para uma intervenção de restauro.

Ainda conforme Carbonara, na medida em que não há o correto discernimento sobre o caráter do patrimônio edificado, abre-se um precedente para as mais diferentes formas de utilização desvinculadas da disciplina da restauração e conseqüentemente da preservação. Essas operações de caráter diverso denominadas "recuperação" (reestruturação, requalificação, reutilização, reciclagem, dentre outras) somente poderiam ser aplicadas exclusivamente àquelas edificações 
em que não tenha sido reconhecido o valor histórico-artístico (CARBONARA, 1997, p. 375).

Concluímos, portanto, que a questão do uso daquelas edificações entendidas enquanto bem cultural deve ser abordada sob a perspectiva interna à disciplina de restauro, o que pode ser sintetizado conforme aponta Carbonara, através de uma expressão assertiva de Miarelli Mariani que indica que a reutilização deve ser interpretada como um meio para a preservação e não como o fim (CARBONARA, 1997, p. 375; KÜHL, 2005, p. 186). O monumento, analisado corretamente por meio de um juízo de valor crítico pode revelar a destinação mais adequada à vocação da edificação, que não é necessariamente o uso original, ainda que este seja preferível quando possível conservá-lo ou repropô-lo, respeitando a realidade material e espiritual do monumento.

\section{Patrimônio industrial}

A partir dessas considerações em relação às teorias preservacionistas e à forma com que o uso é abordado nessa instância, chega-se à problemática, apontada por diversos pesquisadores, que é o reconhecimento do valor dos "bens culturais", principalmente em obras mais recentes.

Embora existam incipientes iniciativas anteriores, o patrimônio industrial só passou a ser efetivamente considerado como bem cultural a partir de 1950 na Inglaterra, quando importantes testemunhos foram demolidos. Nesse contexto, os movimentos para a valorização e preservação do patrimônio industrial relacionaram-se ao campo disciplinar denominado "arqueologia industrial" cujo objetivo é estudar as mudanças sociais, econômicas, e culturais a partir da interpretação das evidências materiais do vasto legado industrial, que envolve conjuntos edificados relacionados com a extração de matéria prima, processamento, produção, armazenamento, transporte, produção energética, dentre outros.

Durante a década de 1970, encontros internacionais incorporaram discussões sobre o valor cultural e documental desse patrimônio. Desde 1972 ocorreram conferências trienais específicas sobre o tema, no III Congresso Internacional sobre Patrimônio Industrial (Suécia - 1978) foi criado o TICCIH (The International Committee for the 
Conservation of the Industrial Heritage), organização mundial voltada à proteção, investigação e documentação desse patrimônio. Em 1978, o Comitê do Patrimônio Mundial da UNESCO inscreveu o primeiro exemplar de caráter industrial em sua lista, a Mina de Sal Wieliczka na Polônia. A partir daí, outros sítios têm sido sistematicamente incluídos demonstrando uma evolução na percepção ao valor cultural desses remanescentes.

O crescente interesse em relação a esse patrimônio nas últimas décadas pode ser sintetizado na formulação da Carta de Nizhny Tagil, em 2003 pelo $\mathrm{TICCIH}$, em que são apresentadas definições, valores, importância da identificação, proteção legal, e também algumas disposições sobre intervenções como manutenção, conservação. Não há, porém, um aprofundamento conceitual mediante as teorias preservacionistas, há somente uma menção sobre a necessidade da leitura da Carta de Veneza (1964) como documento referencial. Sobre a "reutilização" a Carta de Nizhny Tagil dispõe:

4.III - [...] A adaptação harmônica e a reutilização pode ser uma forma adequada e econômica de assegurar a sobrevivência dos edifícios industriais, e deve ser promovida mediante os controles legais, os conselhos técnicos, as bolsas e os incentivos fiscais adequados. (TICCIH, 2003).

5.IV - [...] Os novos usos devem respeitar o material significativo e manter os padrões originais de circulação e atividade, e deve ser tão compatível com o uso original ou principal quanto seja possível. É recomendável habilitar uma área onde se represente o uso anterior. (TICCIH, 2003).

Considerando a inclusão de remanescentes industriais ao conceito de "bem cultural" pode-se perscrutar as razões pelas quais esse patrimônio é comumente interpretado de forma limitada, que não abarca a totalidade de suas características documentais e culturais, para então verificar as formas de apropriação recorrentes, o que está diretamente vinculado à questão do uso como meio para a preservação.

Não só a proximidade temporal condiciona a falta de consciência de valor, como a produção posterior à Revolução Industrial apresenta um caráter diverso da criação artística anterior. Características como a serialidade e a possibilidade de reprodução do produto industrial, podem induzir a interpretações errôneas como a falta da noção 
de originalidade e a possibilidade de substituição dos mesmos sem perdas à história.

Essa dificuldade de reconhecimento do valor histórico-artístico das obras mais recentes, segundo Simona Salvo, reiterando as colocações de Carbonara já apresentadas, são mais suscetíveis a intervenções com preocupações de meras adaptações às exigências contemporâneas de uso, conforto ou segurança, subjugando o valor documental às exigências de caráter econômico e funcional:

A casuística demonstra que as intervenções mais freqüentes oscilam, indo: da demolição, justificada de variadas maneiras, ao abandono do edifício, com as relativas conseqüências deletérias; do exercício de uma manutenção inconsciente, à adequação às normas conduzidas sem atenção para com a qualidade da obra existente; [...]. (SALVO, 2007, p. 143).

Além da dificuldade de reconhecimento do valor histórico-artístico, os edifícios do patrimônio industrial são potencialmente "reutilizáveis" pelas suas próprias características espaciais como a amplitude e a relativa versatilidade: "[...] os edifícios isolados, em geral de construção sólida, sóbria e de manutenção fácil são facilmente adaptáveis às normas de utilização atuais e se prestam a múltiplos usos, públicos e privados" (CHOAY, 2001, p. 219). Adiciona-se ainda o potencial especulativo que reside no valor imobiliário dos terrenos, pois, as áreas industriais são, geralmente, grandes porções em posições estratégicas dotadas de ampla infraestrutura.

Essas características fazem com que, em muitos casos, as edificações sejam encaradas principalmente pelo potencial econômico agregado, muito mais que pelo potencial sócio-cultural. Dessa forma, esse patrimônio vem sendo objeto de adaptações a diversos usos, como escritórios, restaurantes, mercados, centros culturais, centros esportivos, hotéis, habitação, dentre outros, demonstrando uma intensa viabilidade econômica. Porém, muitas vezes, há uma tendência a desconsiderar o existente ou um pseudo-interesse pela restauração com o intuito de construir novos empreendimentos induzindo a escolha de novos usos (RUFINONI, 2004, p. 154). 
Tendo em vista a dificuldade de reconhecimento do valor cultural do patrimônio industrial e suas características arquitetônicas que ensejam um grande potencial espacial e econômico, serão apresentados quatro cenários identificados na prática de apropriação deste patrimônio: remanescentes com a manutenção da atividade inicial (seja produtiva, transporte, produção energética, etc.); grandes áreas abandonadas com potencialidade de demolição; edifícios e áreas com usos adaptados, ou ainda, áreas ou edifícios museificados. Há uma profusão de exemplos internacionais e nacionais apresentados em reuniões científicas especializadas sobre o tema que se enquadram principalmente nas últimas duas categorias identificadas. Para a exemplificação dessas categorias nos concentraremos no amplo acervo industrial da cidade de São Paulo.

\section{As formas de apropriação do patrimônio industrial na cidade de São Paulo}

A cidade de São Paulo, o maior centro industrial da América Latina, que vem sofrendo nas últimas décadas, um desaceleramento de sua atividade industrial constitui um campo profícuo para a análise das questões funcionais e a preservação do patrimônio industrial. Para tanto, tomamos como referência os conjuntos fabris tombados ou em processo de análise pelo órgão de proteção municipal da cidade de São Paulo (Conselho Municipal de Preservação do Patrimônio Histórico, Cultural e Ambiental da Cidade de São Paulo - CONPRESP) (1).

Primeiramente, é importante salientar que na legislação brasileira, o tombamento é o instrumento jurídico de proteção patrimonial por excelência que surge com 0 decreto-lei $n^{\circ} 25$ de 30.11.1937 redigido por Rodrigo M. F. de Andrade. Os aspectos jurídicos desse instrumento enfocam principalmente a questão de propriedade e não se detém em relação à particularidade da função dos bens arquitetônicos, pois ao tombamento não compete determinar a permanência de usos nos bens, ainda que possa regulamentar determinadas funções.

No âmbito municipal, o tombamento é regido pelas leis $\mathrm{n}^{\circ} 10.032$ de 27.12 .1985 e $\mathrm{n}^{\circ}$ 10.236 de 16.12.1986, que alteram alguns dispositivos da anterior. Neste caso a definição da função das edificações também está atrelada às regulamentações do órgão de preservação municipal (CONPRESP) cujas atribuições são, entre outras: Art. $2^{\circ}$ - VII "Promover a estratégia de fiscalização da preservação e do uso dos bens 
tombados" (SÃO PAULO, 1985). Em outro ponto, fica estabelecido: Art. 110 "As resoluções de tombamento definitivo de bens culturais e naturais devem incluir diretrizes diferenciadas de utilização e preservação nos casos em que tais indicações se fizerem necessárias" (SÃO PAULO, 1985).

Tendo essa referência, é possível analisar agora na cidade de São Paulo as quatro categorias de uso acima identificadas para o patrimônio industrial. A princípio, grande parte dos conjuntos fabris encontra-se em estado de deterioração e abandono devido à perda de função como o caso da Companhia Antártica Paulista (FIGURA 01). A perda do uso industrial deriva de uma complexa conjuntura envolvendo aspectos políticos, sociais, culturais e, sobretudo, econômicos, decorrentes da evolução urbana da capital paulista. Entretanto, dois momentos foram decisivos: a mudança da implantação das indústrias dos eixos ferroviários para os rodoviários na década de 1950 e a mudança do perfil econômico da cidade de São Paulo de embasamento industrial para serviços a partir da década de 1980, em decorrência das alterações mundiais do processo produtivo.

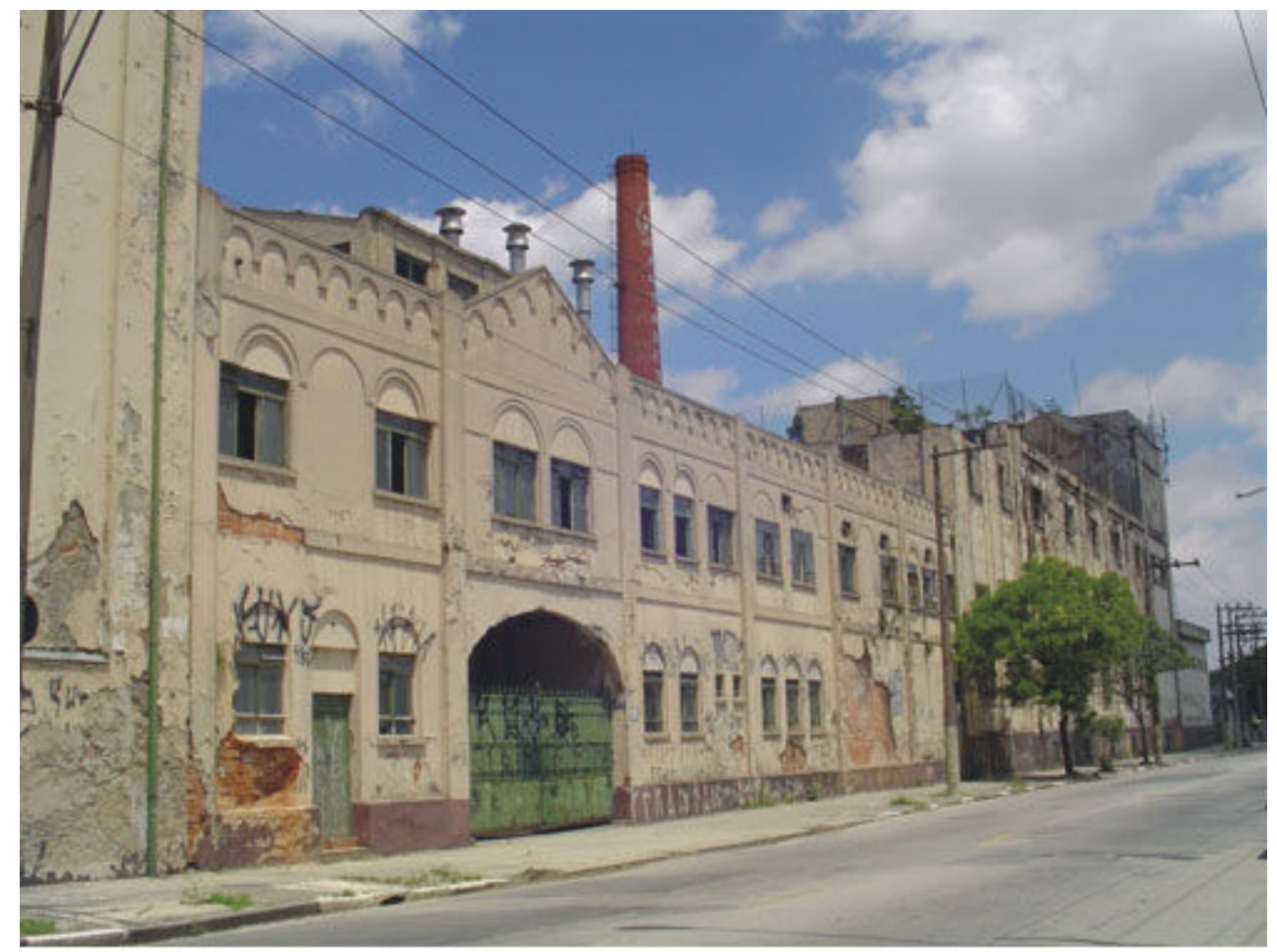

FIGURA 01 - Companhia Antártica Paulista, atualmente sem uso. APT (Abertura de Processo de Tombamento) 09/07. Fotografia: Angela Rösch Rodrigues, 2009. 
De um modo geral, mundialmente os grandes complexos industriais abandonados relacionam-se ao denominado processo de desindustrialização, que foi desencadeado com a crise do petróleo na década de 1970. Esse quadro é explicado a partir da evolução do sistema de produção denominado "fordismo" baseado na produção em massa através de linhas produtivas para a "acumulação flexível" que se apoia na flexibilidade dos processos de trabalho, mercados, produtos e padrões de consumo (HARVEY, 1996, p. 140). Assim, áreas indústrias inteiras do século 19 e início do 20 tenderam ao declínio já que as empresas necessitavam de estruturas mais adequadas às novas demandas. Em decorrência desse processo surgiram os denominados "cinturões de ferrugem" (HOBSBAWM, 1995, p. 297), símbolos de um passado recente, em alguns casos valorizadas enquanto patrimônio industrial.

$\mathrm{Na}$ capital paulista, há também diversos conjuntos fabris que passaram por intervenções com alteração de uso, como o Cotonifício Crespi na Mooca, com parte das edificações convertidas em Hipermercado (FIGURA 02), a antiga fábrica da Alpargatas adaptada para sediar um campus universitário, o Tendal da Lapa utilizado como subprefeitura da Lapa (FIGURA 03), o antigo Matadouro da Vila Mariana transformado em Cinemateca, a Casa das Caldeiras do conjunto das Indústrias Francisco Matarazzo adaptada para um espaço de eventos, o antigo Moinho Minetti Gamba com parte das edificações utilizada para casa de shows, o próprio SESC Pompeia (FIGURA 04), uma das intervenções pioneiras na cidade em que remanescentes industriais foram adaptados a um programa cultural, dentre outros. 


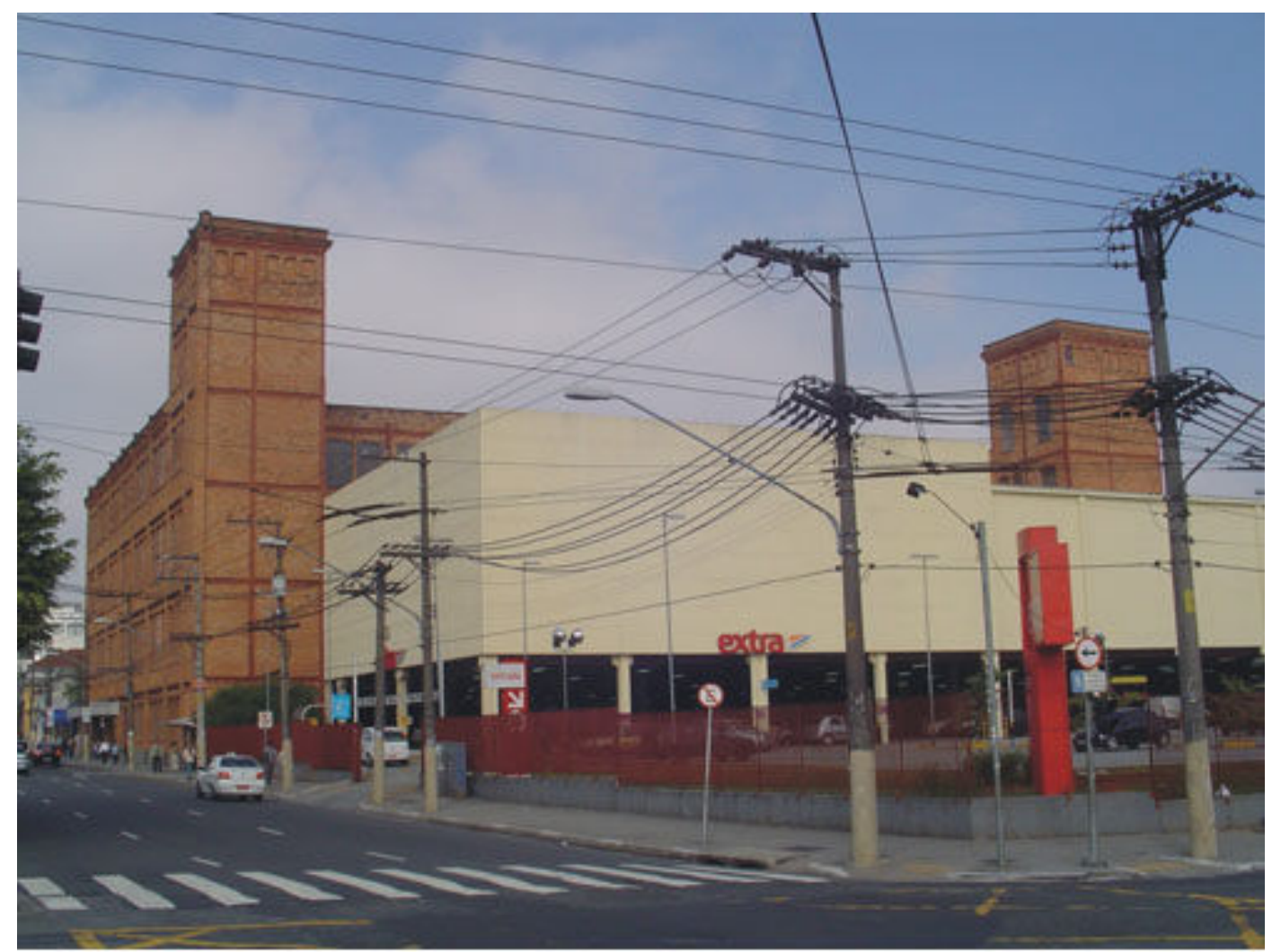

FIGURA 02 - Parte das instalações do antigo Cotonificio Crespi convertido em Hipermercado. ZEPEC (Zona Especial de Proteção Cultural) 26/04. Fotografia: Angela Rösch Rodrigues, 2009. 


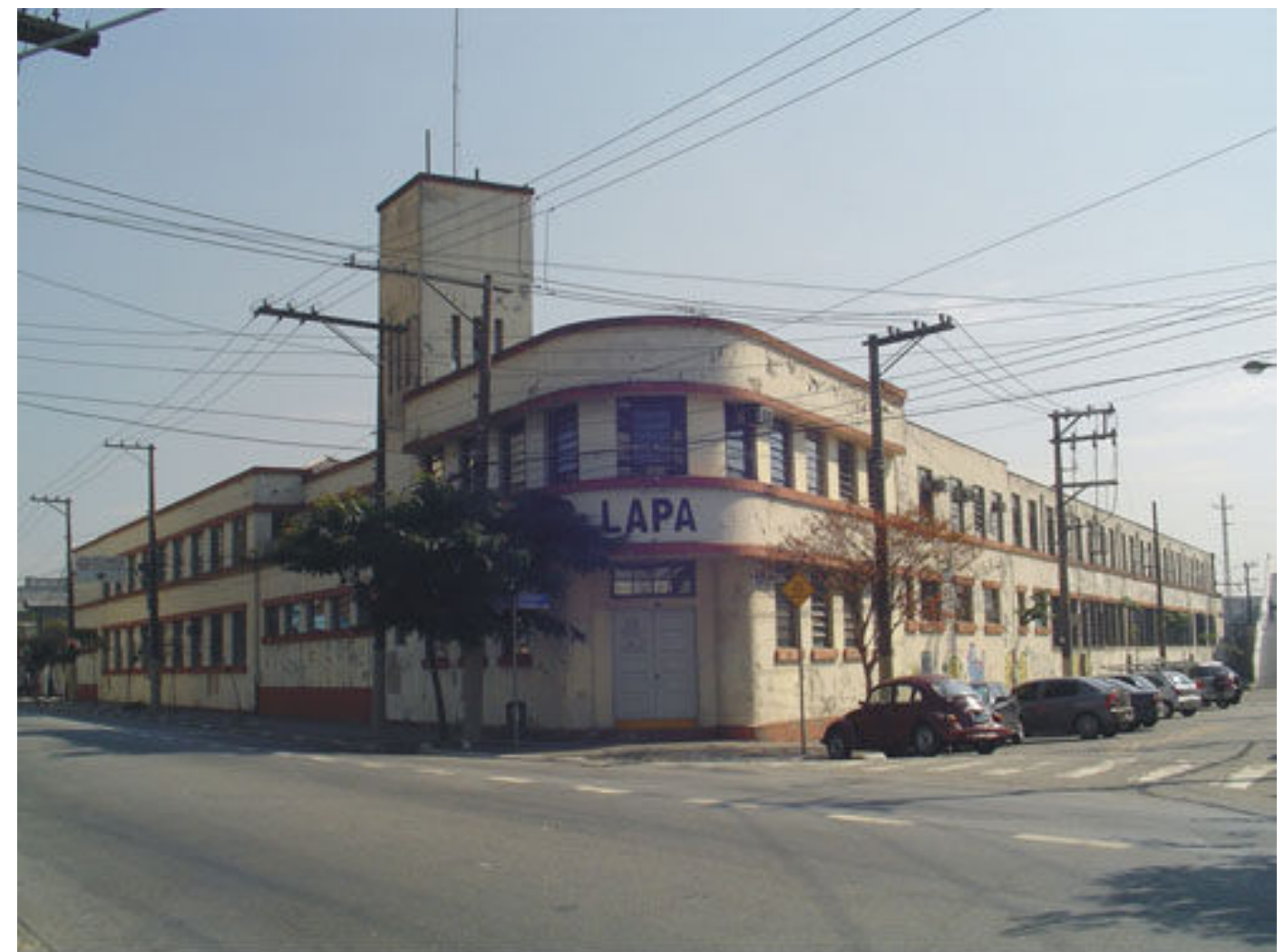

FIGURA 03 - Tendal da Lapa, atualmente recebe instalações da Subprefeitura da Lapa. Resolução de Tombamento 10/07. Fotografia: Angela Rösch Rodrigues, 2009.

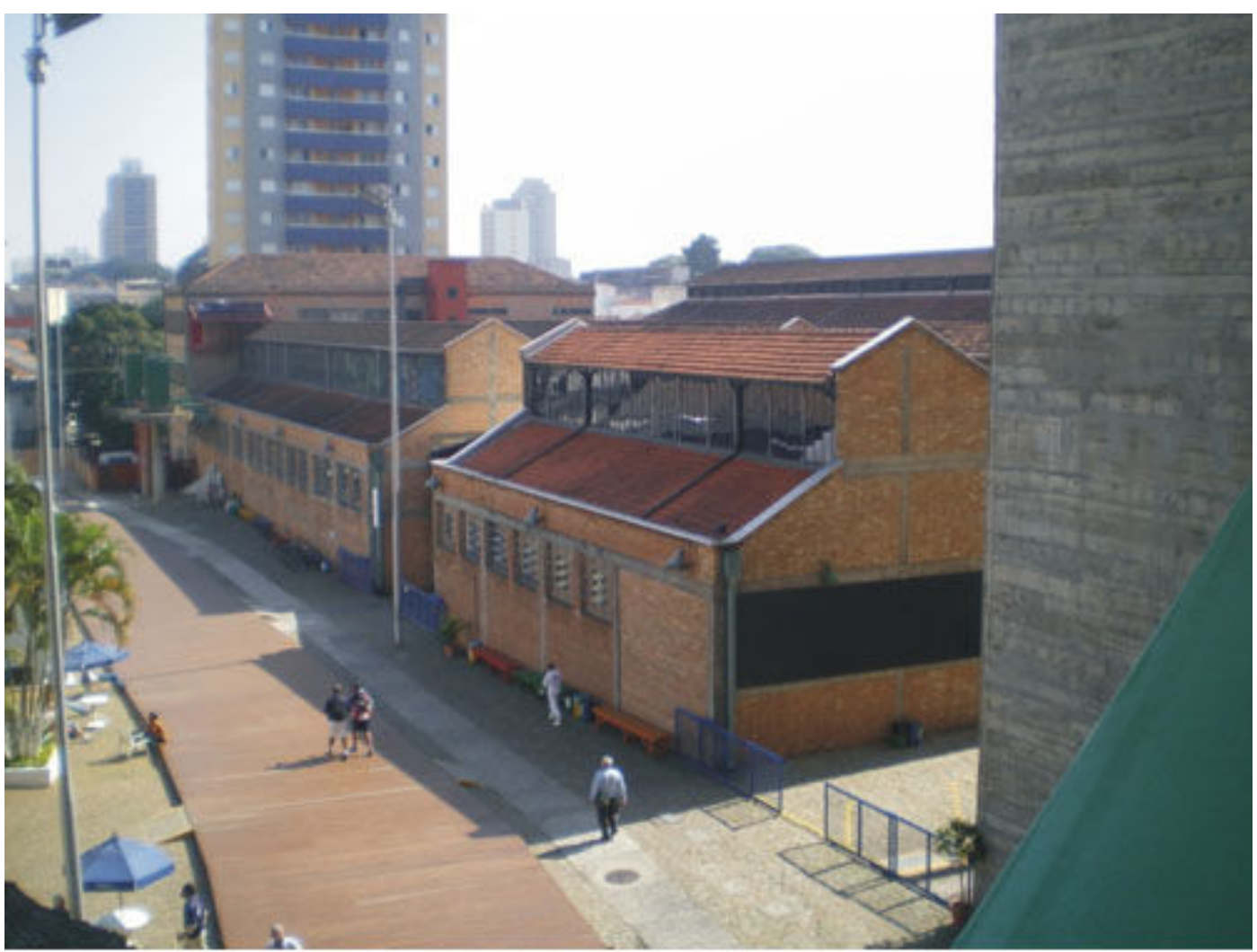

FIGURA 04 - Parte das instalações do SESC Pompéia. Resolução de Tombamento 05/09. Fotografia: Débora Nogueira de Săo José, 2009. 
A mudança de uso para a reinserção e revalorização dos antigos remanescentes ou áreas industriais deve ser entendida dentro do contexto proveniente do período de desindustrialização já mencionado, que proporcionou uma tendência à mudança de perfil de bairros, cidades e regiões inteiras antes dedicadas a atividades produtivas.

No que tange à preservação, a mudança de função envolve uma avaliação criteriosa. O novo programa não basta ser necessariamente designado por homologia à sua destinação original (CHOAY, 2001, p. 219). Além de ser "nominalmente compatível" (KÜHL, 2005, p. 189), deve considerar e compreender a integridade e historicidade das edificações, preservando valores e características da concepção original. A compatibilização entre a infraestrutura edificada e o novo uso demanda trabalhos técnicos acurados e, eventualmente, alterações dispendiosas.

Na categoria da museificação relacionada à memória industrial há a interessante intervenção no Complexo da Figueira, em que parte das estruturas (balões) foram destinadas a um espaço expositivo onde é apresentada a documentação referente à memória da utilização do gás na cidade.

A criação de museus com temática industrial e tecnológica se relaciona diretamente ao próprio processo da compreensão do significado e da valorização desse patrimônio. Essa forma de apropriação é uma variação da apresentada anteriormente, já que também envolve a mudança da função original. Porém, a proposta pedagógica e cultural desse programa é mais evidente e vincula-se estritamente ao cumprimento de uma função social muito relevante às práticas preservacionistas.

Ainda na cidade de São Paulo é possível verificar importantes remanescentes industriais com parte de suas edificações oficialmente protegidas, que mantêm ou mantiveram até recentemente o uso fabril, ainda que com diversas adaptações decorrentes das necessidades do desenvolvimento tecnológico. Dentre eles, destacamos a Fábrica Goodyear (antiga Fábrica Maria Zélia) (FIGURA 05), a Saint Gobain (antiga Vidraria Santa Marina) (FIGURA 06) e a Companhia Melhoramentos de São Paulo (uso fabril até os primeiros meses de 2008) (2) (FIGURA 07). 


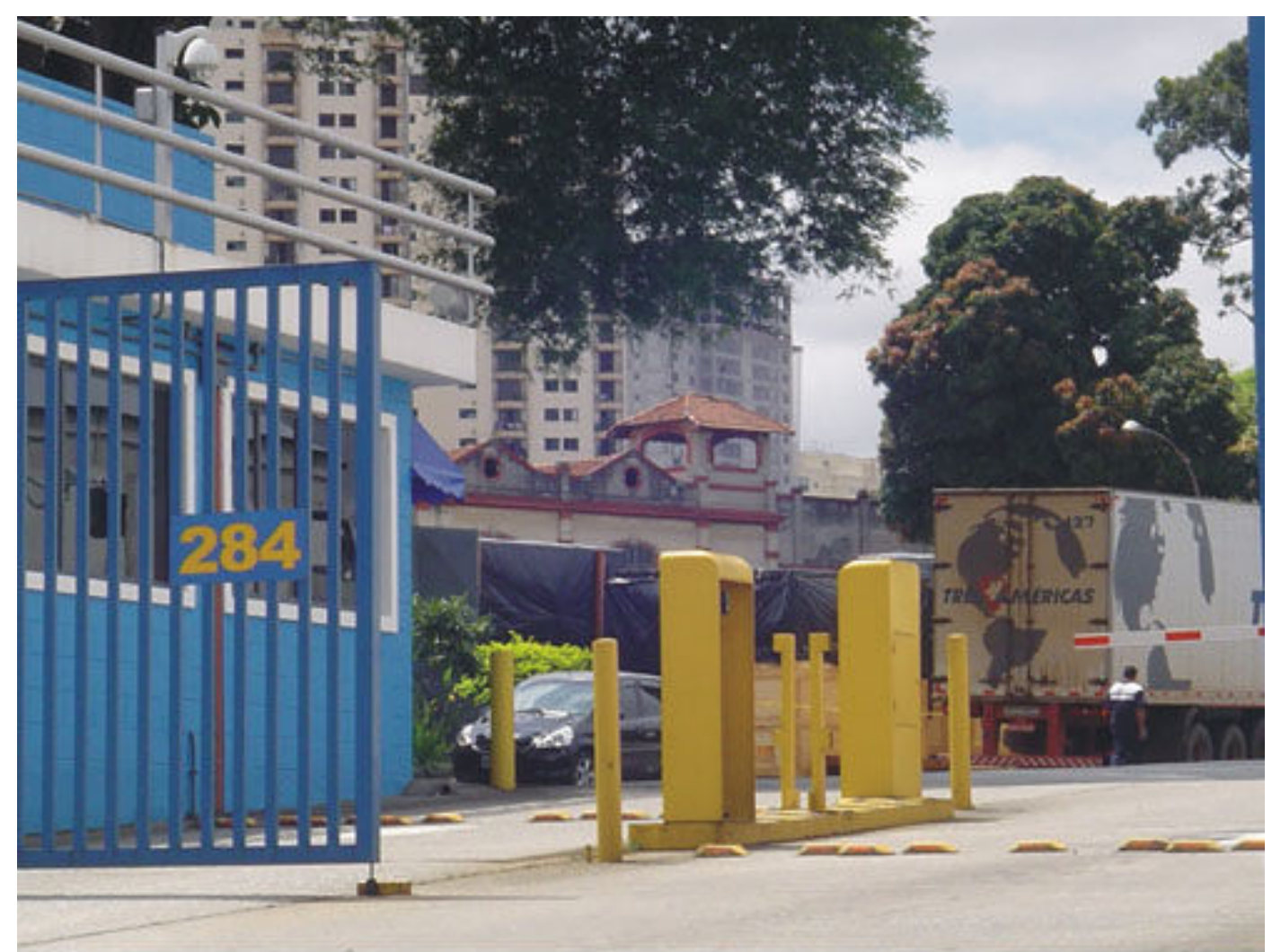

FIGURA 05 - Antiga Fábrica Maria Zélia, Companhia Goodyear do Brasil desde a década de 1930. Ao fundo edificaç̋̃es tombadas. Resoluçăo de Tombamento 39/92. Fotografia: Angela Rösch Rodrigues, 2009.

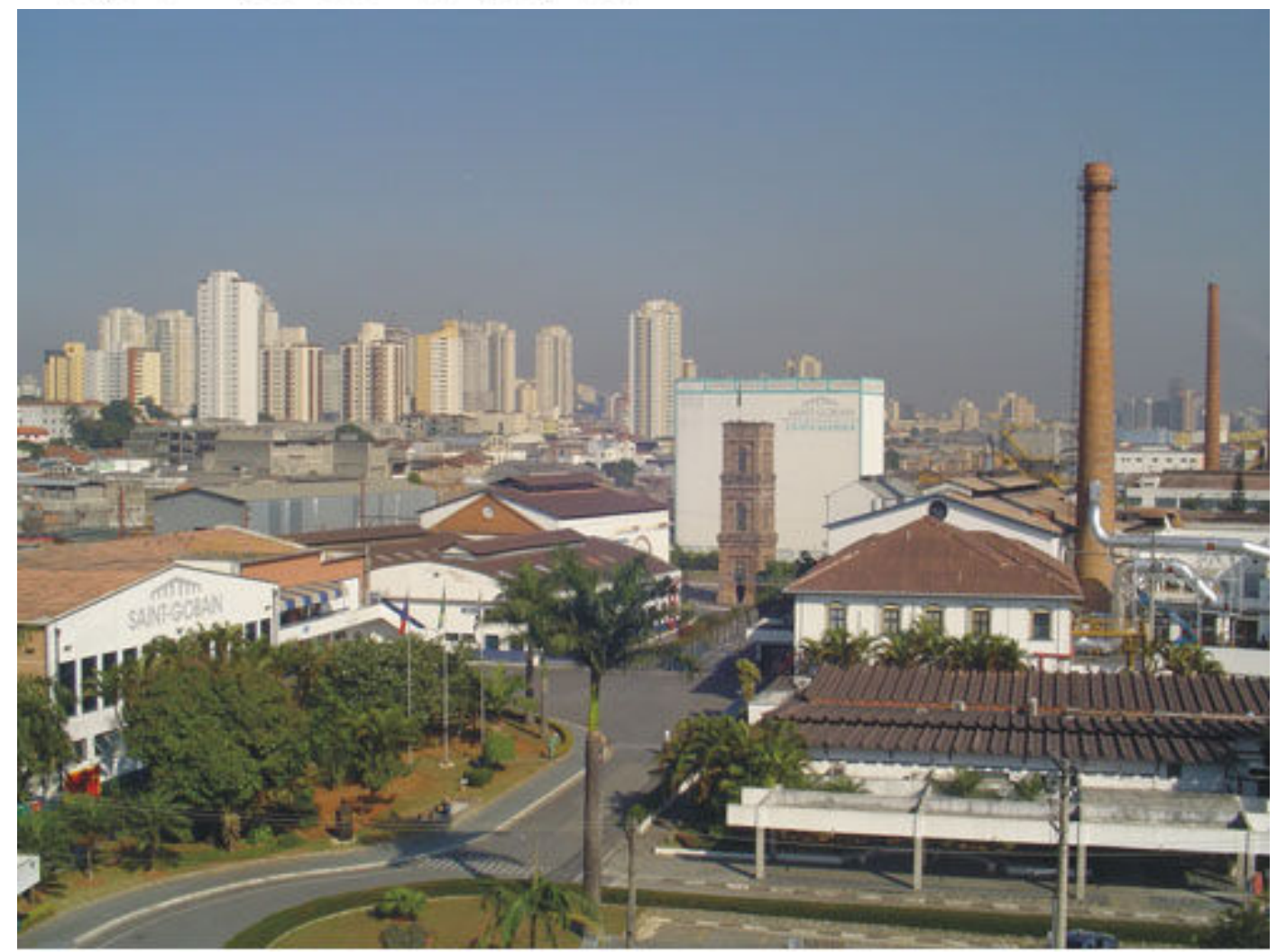

FIGURA 06 - Conjunto das edificaçбes da Saint - Gobain, antiga Vidraria Santa Marina. Remanescentes tombados: Torre de energia; duas chaminés (fornos 5 e 20) e dois edifícios (Amazonas e São Paulo). Resoluçăo de Tombamento 05/09. Fotografia: Angela Rösch Rodrigues, 2008. 


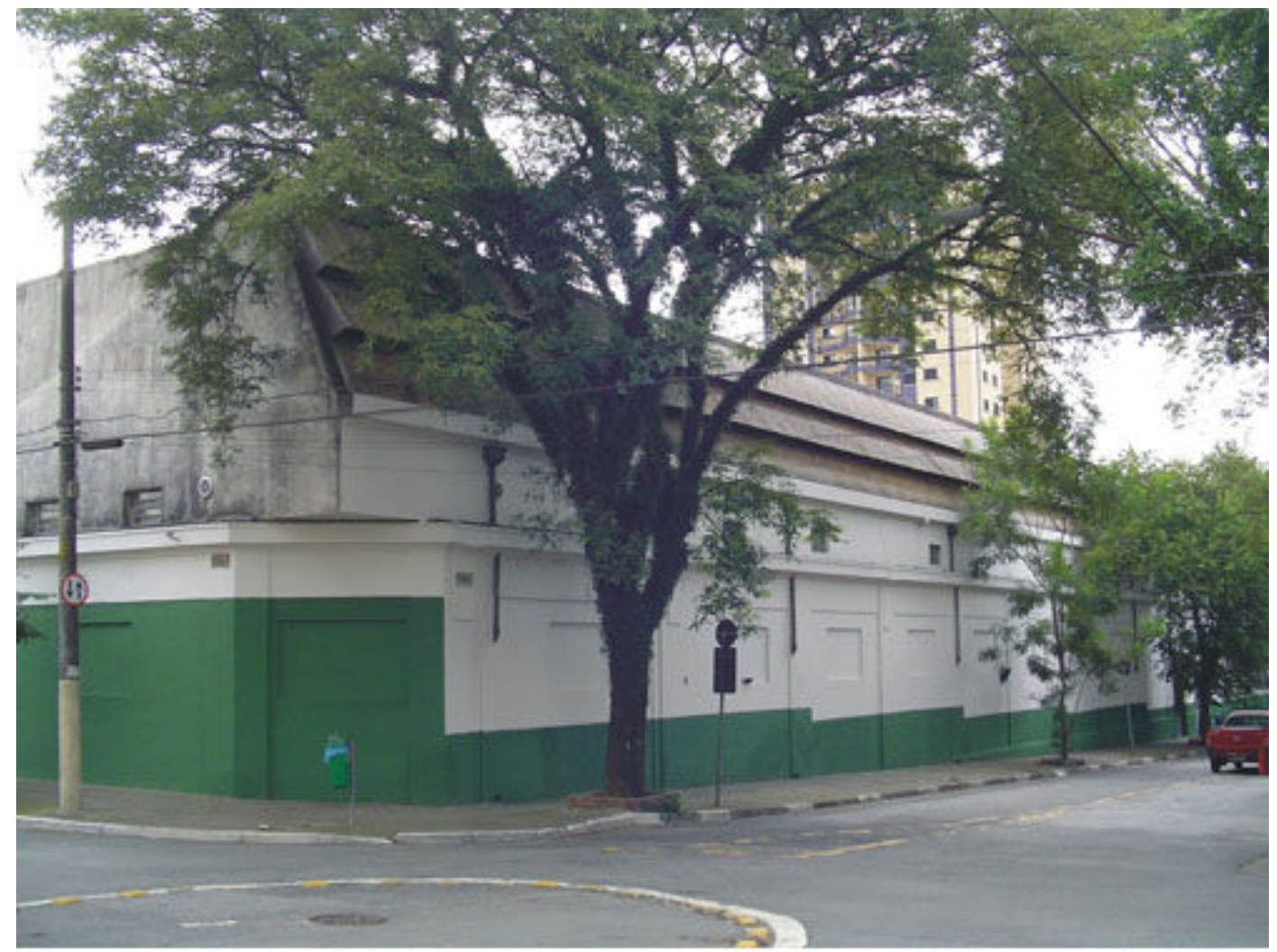

FIGURA 07 - Parte das instalações gráficas da Companhia Melhoramentos de São Paulo, atualmente subutilizado. A resolução de tombamento 05/09 inclui somente o prédio administrativo. Fotografia: Angela Rösch Rodrigues, 2009.

De um modo geral, desconsidera-se a possibilidade da manutenção da atividade original na preservação do patrimônio industrial por alguns fatores. A princípio, a própria ação dos órgãos de preservação tende a começar com imóveis desativados, que estão abandonados e passam a correr maior risco de mutilação ou desaparecimento legitimando a proteção antes da perda irreparável. Além disso, a possibilidade de alteração da função dos remanescentes industriais pode, num primeiro momento, se demonstrar como alternativa mais condizente à mudança de perfil econômico da cidade de São Paulo, com maior ênfase no setor terciário, como apresentado anteriormente, bem como atender mais diretamente à função social da preservação patrimonial que, geralmente, se traduz em atividades culturais.

A despeito de compatibilizações com normas ambientais, de segurança, salubridade dentre tantos aspectos pertinentes à análise da viabilidade da manutenção da atividade industrial que devem ser criteriosamente avaliados, no que tange à preservação arquitetônica, essa categoria de apropriação não deixa de ser uma alternativa tão possível e viável quanto as anteriores, desde que sejam observados 
princípios de intervenção na justa perspectiva do campo da preservação cujo objetivo principal é a conservação do patrimônio cultural da melhor forma possível às outras gerações.

Para uma avaliação mais criteriosa, o significado do patrimônio industrial deve ser vislumbrado tendo como referência o contexto urbano em que está inserido, essa relação também está destacada na Carta de Nizhny Tagil: "4 ii - Programas para a conservação do patrimônio industrial devem ser integrados nas políticas econômicas de desenvolvimento assim como na planificação regional e nacional." Nesse sentido, pode-se analisar na cidade de São Paulo, alguns dos dispositivos legais que incidem sobre a regulamentação do uso e ocupação do solo. Nas atuais disposições do Plano Diretor Estratégico para antigas áreas predominantemente industriais, como nos distritos da Mooca e Lapa (3), verifica-se um incentivo à diversificação do uso do solo urbano para o setor terciário (serviços) ou para o uso residencial refletindo diretamente a mudança do perfil econômico da cidade. Muitas dessas antigas áreas e suas edificações industriais ficam, então, ameaçadas pela demolição para liberação de área útil para novos empreendimentos (FIGURA 08), ou ainda, expostas a intervenções cuja finalidade é a simples reutilização, sem maiores preocupações com a efetiva preservação patrimonial. 


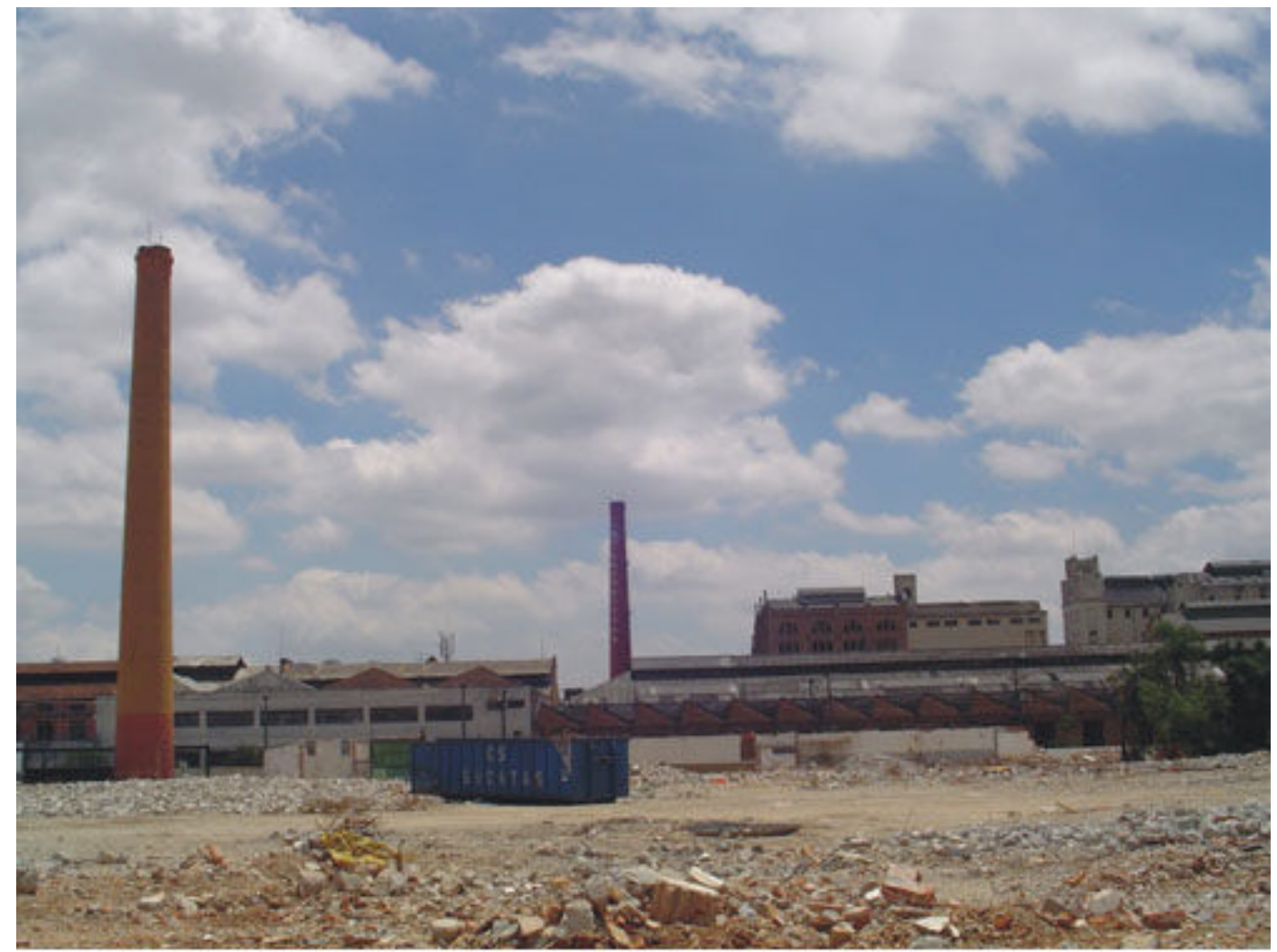

FIGURA 08 - Área demolida da antiga Companhia de Refinadores União na Rua Borges de Figueiredo $\times$ Rua João Antonio de Oliveira. A chaminé (lado esquerdo) segue com abertura de processo de tombamento - 07/08. Fotografia: Angela Rösch Rodrigues, 2009.

De uma forma geral, reiterando as colocações apresentadas anteriormente sobre o problema de reconhecimento de valor das obras mais recentes e o estabelecimento de critérios de intervenção que abranjam a questão do uso, pode-se constatar que, embora esses exemplares estejam sob alguma forma tutelados por um órgão municipal e tendo-se como pressuposto que haja um reconhecimento dos mesmos enquanto "bem cultural", o aspecto do uso, na maioria das vezes não é vislumbrado sob a perspectiva da restauração.

Assim, importantes questões que vêm sendo repetidas pelos principais teóricos preservacionistas se reforçam para o contexto atual: em que medida se processa a diferença na percepção dos monumentos de um passado mais remoto e de um passado mais recente condicionando as ações de intervenção e adaptação à contemporaneidade? Qual é a função mais adequada, ou os usos que melhor se coadunam com a preservação de um bem? No que tange diretamente ao patrimônio industrial podemos acrescentar algumas questões: a manutenção da atividade fabril 
pode ser uma alternativa viável para a preservação de um bem? Que medidas poderia o poder público adotar para incentivar a permanência dessas indústrias ou a ocupação desses bens por outras fábricas? Como o poder público poderia colaborar para que as empresas reconhecessem o valor de seu patrimônio edificado e de fato o preservassem?

\section{Considerações Finais}

Conforme apresentado, o entendimento de que um uso seja necessário para os bens arquitetônicos atrela a questão da funcionalidade de forma irredutível às diversas discussões teóricas preservacionistas ao longo da história. Com efeito, como destaca Carbonara o "restauro arquitetônico" relaciona-se com diversos aspectos culturais (artísticos, formais, linguísticos) sociais, políticos, econômicos e urbanísticos, dos quais deriva a questão da funcionalidade. A avaliação de todas essas instâncias é necessária para a efetiva preservação em bens de valor históricoartístico.

Assim, na medida em que o patrimônio industrial é reconhecido como bem cultural a ser tutelado pelos órgãos legais, a função deve ser entendida dentro da perspectiva do campo disciplinar da restauração, devendo-se avaliar qual uso seja mais compatível para a efetiva preservação a partir de um estudo crítico de caso a caso. E para aqueles exemplares ainda em atividade, o grande desafio se constitui em coadunar o incremento das necessidades produtivas com o patrimônio edificado, sob a ótica do restauro preventivo como postulou Brandi. Dessa forma, a efetiva preservação arquitetônica do patrimônio industrial deve ser vislumbrada de modo integrado, através de projetos que englobem não só criteriosamente o aspecto funcional, mas também, princípios como a mínima intervenção, a distinguibilidade, dentre outros postulados em cartas patrimoniais, bem como a dimensão urbana desse patrimônio e sua correlação com a planificação territorial.

Esse artigo pretendeu apresentar pistas para uma reflexão, que se faz necessária, sobre as formas de intervir em reconhecidos "bens culturais", e seu limiar com a questão do uso, principalmente para o patrimônio mais recente e mais especificamente no que se refere ao patrimônio industrial, pois o fato de que, eventualmente, o valor documental seja predominante nesses grandes conjuntos 
edificados, não se invalida o embasamento nos instrumentos teóricos para qualquer tipo de intervenção.

Ainda que sejam obras de conservação, manutenção preventiva ou restauração deve-se ter em conta o desenvolvimento de todo o campo disciplinar referente à preservação que dispõe de uma profícua produção teórica desenvolvida a partir do século 19, bem como princípios estabelecidos em documentos de vigência internacional. Considerar a pertinência do uso, a partir de estudos acurados e de um juízo crítico em relação ao caráter do patrimônio, é um fator decisivo para se determinar a vocação e a compatibilidade espacial de um conjunto edificado com vistas à sua restauração, cujo objetivo é a preservação do bem arquitetônico em sua maior integridade possível.

\section{Notas}

(1) Como referência, foram usados os dados do CONPRESP divulgados no Índice Geral:

<http://www.prefeitura.sp.gov.br/cidade/secretarias/cultura/conpresp/indice_geral/index.php?p=1142>

E nas Resoluções divulgadas no sítio:

<http://www.prefeitura.sp.gov.br/cidade/secretarias/cultura/conpresp/legislacao/resolucoes/index.php?p=1137>

(2) Remanescentes da Antiga Vidraria Santa Marina e da Companhia Melhoramentos de São Paulo estavam sendo estudados pelo CONPRESP para tombamento desde 2004, pois eram enquadrados como ZEPEC (Zonas Especiais de Proteção Cultural). Recentemente, na Resolução de Tombamento 05/09 duas chaminés, dois edifícios e a torre de energia da antiga Vidraria Santa Marina foram efetivamente tombados enquanto que o galpão da atividade gráfica da Companhia Melhoramentos de São Paulo foi excluído, sendo tombado somente o prédio administrativo. Ver maiores detalhes sobre a respectiva resolução no sítio do CONPRESP:

<http://www.prefeitura.sp.gov.br/cidade/secretarias/cultura/conpresp/legislacao/resolucoes/index.php?p=1137>.

(3) Como referência foram usados os dados referentes às Subprefeituras da Lapa e Mooca publicados pela SEMPLA:

SÃO PAULO (cidade). Planos Regionais Estratégicos do Município de São Paulo - Subprefeitura Lapa (PRES LA). Série Documentos. São Paulo: SEMPLA, 2004.

Planos Regionais Estratégicos do Município de São Paulo - Subprefeitura Mooca (PRE MO). Série Documentos. São Paulo: SEMPLA, 2004.

\section{Referências bibliográficas}

BOITO, Camillo. Os restauradores. Cotia, SP: Ateliê Editorial, 2002.

BRANDI, Cesare. Teoria da restauração. Cotia, SP: Ateliê Editorial, 2004. 
CARBONARA, Giovanni. Avvicinamento al restauro. Napoli: Liguori, 1997.

Brandi e a restauração arquitetônica hoje. Desígnio - Revista de História da Arquitetura e do Urbanismo, São Paulo, n. 6, p. 35-47, 2006.

CHOAY, Françoise. A alegoria do patrimônio. São Paulo: UNESP, 2001.

CURY, Isabelle.(Org.). Cartas patrimoniais. Rio de Janeiro: IPHAN, 1999.

GIOVANNONI, Gustavo. Restauro dei Monumenti. In: Enciclopedia Italiana di Scienze, Lettere ed Arti. Roma: Istituto della Enciclopedia Italiana (Treccani), 1936. p. 127-130.

HARVEY, David. Condição pós-moderna: uma pesquisa sobre as origens da mudança cultural. São Paulo: Edições Loyola, 1996.

HOBSBAWM, Eric. Era dos extremos: o breve século XX - 1914-1991. São Paulo: Companhia das Letras, 1995.

ICOMOS. Carta de Veneza, 1964. Disponível em:

<http://portal.iphan.gov.br/portal/baixaFcdAnexo.do?id=236>. Acesso em: 30 jan. 2010.

JOKILEHTO, Jukka IImari. A History of Arhitectural Conservation. Oxford: Butterworth-Heinemann, 1999.

KÜHL, Beatriz Mugayar. História e ética na conservação e na restauração de monumentos históricos. Revista CPC (eletrônica), São Paulo, v.1, n. 1, p. 16-40, nov. 2005/abr. 2006. Disponível em:

<http://www.usp.br/cpc/v1/php/wf07 revista capa.php?id revista=2>. Acesso em: 30 jan. 2010.

Preservação da arquitetura industrial em São Paulo: questões teóricas. São Paulo: Faculdade de Arquitetura e Urbanismo, Universidade de São Paulo (FAUUSP), São Paulo, 2005. Relatório Científico.

Preservação do patrimônio arquitetônico da industrialização: problemas teóricos de restauro.

Cotia, SP: Ateliê Editorial, 2008.

Os restauradores e o pensamento de Camillo Boito sobre a restauração. In: BOITO, Camillo. Os restauradores. Cotia, SP: Ateliê Editorial, 2002. p. 9-28.

As transformações na maneira de intervir na arquitetura do passado entre os séculos XV e XVIII: o período de formação da restauração. Sinopses, São Paulo, n. 36, p. 24-36, 2001.

LEMOS, Carlos A. C. O que é patrimônio histórico. São Paulo: Brasiliense, 2006.

PINHEIRO, Maria Lucia Bressan. William Morris e a SPAB. Rotunda (eletrônica), n. 3, p. 22-35, out. 2004.

Disponível em: <http://www.iar.unicamp.br/rotunda/rotunda03.pdf>. Acesso em: 30 jan. 2010.

RIEGL, Alois. // culto moderno dei monumento - II suo carattere e i suoi inizi. Bologna: Nuova Alfa Editoriale, 1990. 
RODRIGUES, Angela Rösch. Cidade e indústria: estudo sobre a relação dos processos de urbanização e industrialização na cidade de São Paulo. In: ENCONTRO NACIONAL SOBRE PATRIMÔNIO INDUSTRIAL, 2., 2009, São Paulo. Anais... São Paulo: Universidade Belas Artes, 2009. CD-ROM.

RUSKIN, John. A lâmpada da memória. Cotia, SP: Ateliê Editorial, 2008.

RUFINONI, Manoela Rossinetti. Preservação do patrimônio industrial na cidade de São Paulo: o bairro da Mooca. Dissertação (Mestrado)-Faculdade de Arquitetura e Urbanismo, Universidade de São Paulo, São Paulo, 2004.

Preservação e restauro urbano: teoria e prática de intervenção em sítios industriais de interesse cultural. Tese (Doutorado)-Faculdade de Arquitetura e Urbanismo, Universidade de São Paulo, São Paulo, 2009.

SALVO, Simona. Restauro e 'restauros' das obras arquitetônicas do século 20: intervenções em arranha-céus em confronto. Revista CPC (eletrônica), São Paulo, v.4, n. 4, p. 139-157, maio/out. 2007. Disponível em: <http://www.usp.br/cpc/v1/php/wf07 revista capa.php?id revista=8>. Acesso em: 30 jan. 2010.

SÃO PAULO (cidade). Planos Regionais Estratégicos do Município de São Paulo - Subprefeitura Lapa (PRES LA). São Paulo: SEMPLA, 2004. (Série Documentos).

Planos Regionais Estratégicos do Município de São Paulo - Subprefeitura Mooca (PRE - MO).

São Paulo: SEMPLA, 2004. (Série Documentos).

SÃO PAULO (cidade). SMC/CONPRESP. Lei N 10.032 de 27 de Dezembro de 1985. Disponível em: <http://www.prefeitura.sp.gov.br/cidade/upload/leis 1003285 e 1023686 1256746494.doc.>. Acesso em: 30 jan. 2010.

SMC/CONPRESP. Lei Nº 10.236 de 16 de Dezembro de 1986. Disponível em: <http://www.prefeitura.sp.gov.br/cidade/upload/leis 1003285 e $1023686 \quad 1256746494 . d o c .>$. Acesso em: 30 jan. 2010.

SOCIEDADE das Nações. Carta de Atenas, 1931. Disponível em:

<http://portal.iphan.gov.br/portal/baixaFcdAnexo.do?id=232>. Acesso em: 30 jan. 2010.

TICCIH. Carta Niznhy Tagil, 2003. Disponível em:

<http://www.patrimonioindustrial.org.br/modules.php?name=News\&file=article\&sid=29>. Acesso em: 30 jan. 2010.

VIOLLET-LE-DUC, Eugène Emmanuel. Restauração. Cotia, SP: Ateliê Editorial, 2000.

\section{Sítios Consultados}

PMSP. SMC - DPH -CONPRESP - Índice Geral: 

em: 30 jan. 2010.

PMSP. SMC - DPH - CONPRESP - Resoluções:

<http://www.prefeitura.sp.gov.br/cidade/secretarias/cultura/conpresp/legislacao/resolucoes/index.php?p=1137>. Acesso em: 30 jan. 2010.

\section{Créditos}

* Arquiteta e Urbanista graduada pela Universidade Mackenzie, mestranda na área de História e Fundamentos da Arquitetura e Urbanismo da Faculdade de Arquitetura e Urbanismo da Universidade de São Paulo (FAU USP). Bolsista FAPESP.

e-mail: angelarr@usp.br

** Arquiteta, professora livre-docente da Faculdade de Arquitetura da Universidade de São Paulo (FAU-USP); exconselheira do Conselho Municipal de Preservação do Patrimônio Histórico, Cultural e Ambiental da Cidade de São Paulo (CONPRESP).

e-mail: junqueira.monica@uol.com.br 